\title{
Diapause-like prolongation of larval duration under short-day photoperiod and low temperature conditions in the silver Y moth, Autographa gamma Linnaeus (Lepidoptera: Noctuidae)
}

\author{
Osamu SAITo ${ }^{\dagger}$ \\ National Agricultural Research Center for Hokkaido Region; Memuro, Hokkaido 082-0071, Japan \\ (Received 28 June 2006; Accepted 14 March 2007)
}

\begin{abstract}
The silver Y moth, Autographa gamma is a well-known migratory insect pest without apparent diapause; however, it overwinters under cold conditions in Hokkaido, Japan. Middle stage larvae are found under deep snow in late winter in this area. To elucidate the winter-adaptation feature of the Hokkaido population, photoperiodic responses were examined at various temperatures $\left(28,23,18,13^{\circ} \mathrm{C}\right)$. There were few differences in the egg and pupal duration between under short-day (12L-12D) and long-day (16L-8D) photoperiods. However, larval duration greatly prolonged under short-day photoperiod than under long-day photoperiod at $13^{\circ} \mathrm{C}$, due to the prolongation of the fourth larval instar.
\end{abstract}

Key words: Silver Y moth; Autographa gamma; prolongation of larval duration; short-day photoperiod; low temperature

\section{INTRODUCTION}

The silver Y moth, Autographa gamma Linnaeus (Lepidoptera: Noctuidae) is a well-known migrant insect pest in Europe. This species overwinters in the Mediterranean regions, Africa, or southern Europe and then migrates northward in summer (summarized by Oku and Kobayashi, 1978).

In Japan, A. gamma is mainly distributed northward and usually produces three generations a year in Hokkaido Island (Kitamura et al., 1989; Kaneko et al., 1990). It is an important insect pest of crops such as sugar beet, cabbage and alfalfa in this area (Torikura, 1991; Kaneko, 1993). Although larval occurrence on crops or wild plants in the southern part of Honshu Island has not been reported, the presence of many adults was recorded in this area (Saito, 1997). These adults were considered to be migrants from indigenous areas like Hokkaido.

The middle instar larvae of $A$. gamma overwinter on their host plants under deep snow for as long as five months in Hokkaido (Kanehira and
Torikura, 1988; Saito, 1988; Torikura, 1991; Kaneko, 1996). The third and fourth instar larvae of the species develop a high level of cold hardiness due to cold hardening; however, larvae in the other instars, egg, or pupa are not sensitive to cold hardening (Kaneko, 1996). It is believed that despite the enhancement of cold hardiness the $A$. gamma found in Hokkaido is unable to survive the long winter. Furthermore, there has been no report that this species exhibits diapause at any stage in its life cycle (Abdinbekova and Akhmedov, 1971). In the present study, the photoperiodic response of eggs, larvae, and pupae in a Hokkaido population of A. gamma were examined at various temperatures.

\section{MATERIALS AND METHODS}

An experimental population of $A$. gamma was derived from females collected using a light trap in Memuro, Hokkaido, Japan, in 1988; this population was reared, and a rearing strain of successive

\footnotetext{
${ }^{\dagger}$ Present address: Department of New Technology Development, Bio-oriented Technology Research Advancement Institution, National Agriculture and Food Research Organization, Tokyo Office, Toranomon-Marine Bldg. 10F, Toranomon 3-18-19, Minato-ku, Tokyo 105-0001, Japan. E-mail: osaito@affrc.go.jp

DOI: $10.1303 /$ aez.2007.391
} 
generations was established in the laboratory under constant temperature $\left(23 \pm 0.5^{\circ} \mathrm{C}\right)$ and a long-day photoperiod (16L-8D) conditions by using a meridic diet (Tsutsui et al., 1989). The second to the fifth generations were used for examination of photoperiodism.

The eggs, larvae, and pupae were kept or reared from oviposition to adult emergence at various temperatures $\left(28,23,18\right.$ or $\left.13^{\circ} \mathrm{C}\right)$, under a longday $(16 \mathrm{~L}-8 \mathrm{D})$ photoperiod, or a short-day $(12 \mathrm{~L}-$ 12D) photoperiod.

The eggs were laid during scotophase and incubated and checked for hatching every morning. The larvae were reared in groups in a Petri dish (diameter: $9 \mathrm{~cm}$ and thickness: $1 \mathrm{~cm}$ ) during the first and second instars or in a plastic container (length: $27.0 \mathrm{~cm}$, width: $17.5 \mathrm{~cm}$, and depth: $8.5 \mathrm{~cm}$ ) during the third, fourth, and fifth instars according to the method described by Tsutsui et al. (1989). Every morning, the larval development was assessed and the number of larvae was counted. The pupation and adult emergence were also checked every morning and the emerging adults were sexed.

\section{RESULTS}

The egg duration of $A$. gamma was shorter at higher temperature conditions (Table 1). Although there were significant differences among the egg durations at different temperatures, no significant differences in the durations were observed in the

Table 1. Egg duration in A. gamma under different temperature and photoperiod conditions

\begin{tabular}{clccc}
\hline $\begin{array}{c}\text { Temper- } \\
\text { ature }\end{array}$ & Photoperiod & $\begin{array}{c}\text { Average } \\
\text { days }^{\mathrm{a}}\end{array}$ & $95 \% \mathrm{CL}^{\mathrm{b}}$ & Number \\
\hline $28^{\circ} \mathrm{C}$ & $16 \mathrm{~L}-8 \mathrm{D}$ & $3.0(3-3)$ & \pm 0.00 & 37 \\
& $12 \mathrm{~L}-12 \mathrm{D}$ & $3.0(3-3)$ & \pm 0.00 & 32 \\
$23^{\circ} \mathrm{C}$ & $16 \mathrm{~L}-8 \mathrm{D}$ & $4.2(4-5)$ & \pm 0.14 & 36 \\
& $12 \mathrm{~L}-12 \mathrm{D}$ & $4.2(4-5)$ & \pm 0.14 & 34 \\
$18^{\circ} \mathrm{C}$ & $16 \mathrm{~L}-8 \mathrm{D}$ & $6.0(6-6)$ & \pm 0.00 & 30 \\
& $12 \mathrm{~L}-12 \mathrm{D}$ & $6.1(6-7)$ & \pm 0.08 & 34 \\
$13^{\circ} \mathrm{C}$ & $16 \mathrm{~L}-8 \mathrm{D}$ & $11.2(11-12)$ & \pm 0.14 & 27 \\
& $12 \mathrm{~L}-12 \mathrm{D}$ & $11.2(11-12)$ & \pm 0.11 & 44 \\
\hline
\end{tabular}

${ }^{a}$ Minimum and maximum values are shown in parentheses.

${ }^{\mathrm{b}}$ No significant difference between the different photoperiods at the same temperature (Student's $t$-test). The egg durations are significantly different at different temperatures under both photoperiods (ANOVA with Tukey's multiple comparisons, $p<0.01$ ).

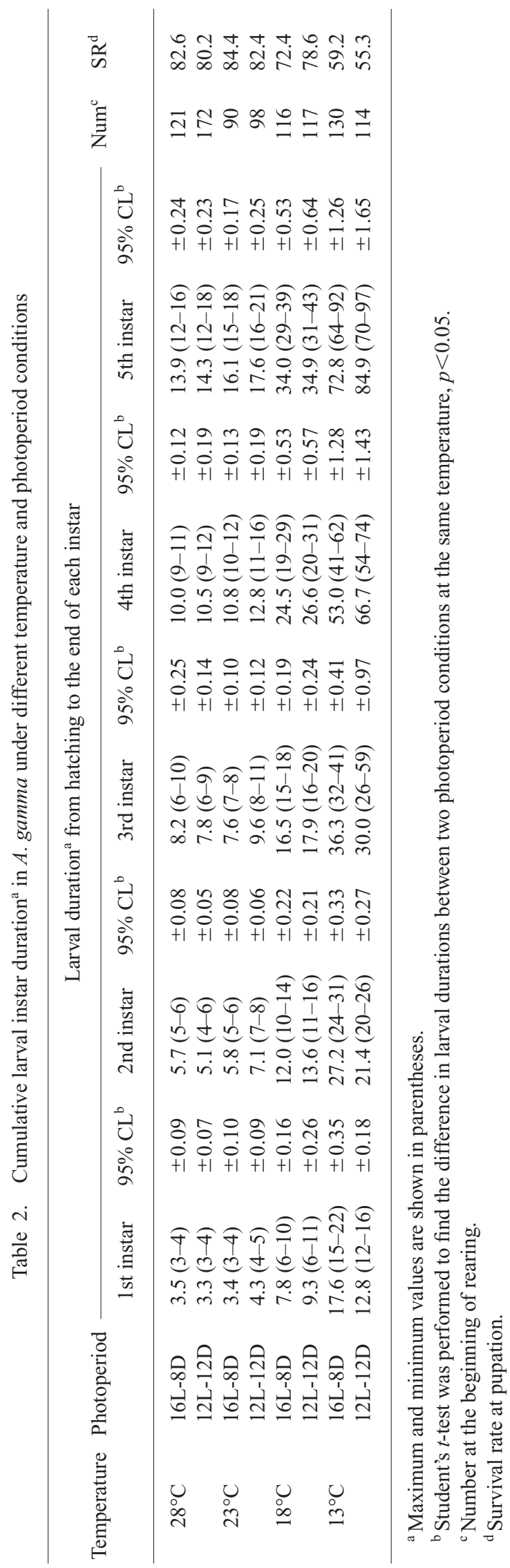


case of different photoperiods at the same temperatures.

The mean duration from hatching to the end of each instar is shown in Table 2. The whole larval duration, indicated as the fifth instar duration in the table, was also shorter at higher temperatures. There were significant differences in all the larval instar durations under different photoperiods at the same temperatures. The differences in the larval instar durations ranged from 0.2 to 0.6 days under different photoperiods at $28^{\circ} \mathrm{C}$. Each larval instar duration under the short-day photoperiod was a little longer than that under the long-day photoperiod at 23 and $18^{\circ} \mathrm{C}$. On the other hand, the first (L1), second (L2), and third instar (L3) durations under the long-day photoperiod were approximately 5 or 6 days longer than those under the short-day photoperiod at $13^{\circ} \mathrm{C}$. On the contrary, the fourth (L4) and fifth instar (L5) durations under the short-day photoperiod were approximately 12 or 14 days longer than those under the long-day photoperiod. Hence, exact L4 duration, calculated from the mean days of L4 duration minus L3 duration, was 16.7 days under the long-day photoperiod and 36.7 days under the short-day photoperiod. The cumula- tive rates of larval instars in $A$. gamma are shown in Fig. 1. The prolongation of L4 duration under the short-day photoperiod at $13^{\circ} \mathrm{C}$ is clearly observed. Moreover, a part of L3 delayed to moult to L4, although almost all L3 moulted from the 26th to 31 st days.

The pupal durations are shown in Table 3. The pupal durations of the females were shorter than those of the males under almost all conditions. At $28^{\circ} \mathrm{C}$, the pupal durations tended to be shorter under the long-day photoperiod than under the short-day photoperiod, whereas at 13,18 and $23^{\circ} \mathrm{C}$, the pupal durations were shorter under the shortday photoperiod than under the long-day photoperiod.

\section{DISCUSSION}

The preimaginal development of $A$. gamma does not include the obligate diapause stage within the common rearing-temperature range (Abdinbekova and Akhmedov, 1971). However, in the present results, L4 duration shows a remarkable prolongation at $13^{\circ} \mathrm{C}$ under the short-day photoperiod. Because developmental zero of larval development in this
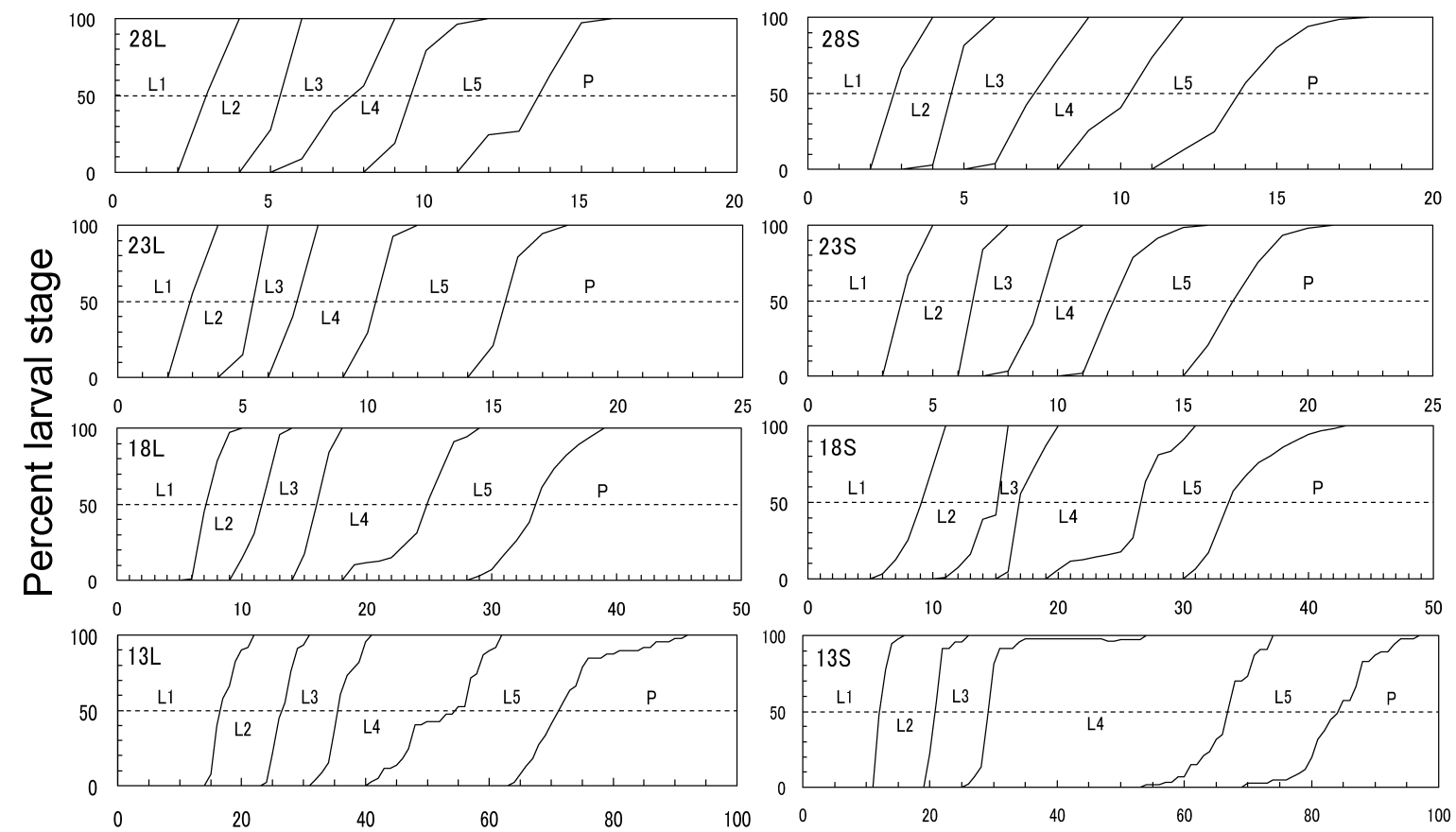

Days after hatching

Fig. 1. Cumulative rate of larval instars in A. gamma under various temperature and photoperiod conditions. The number and uppercase letters denote temperature $\left({ }^{\circ} \mathrm{C}\right)$ and photoperiod (L; long-day photoperiod, S; short-day photoperiod), respectively. L1-L5 and P indicate first-fifth instar larva and pupa, respectively. 
Table 3. Pupal duration in A. gamma under different temperature and photoperiod conditions

\begin{tabular}{|c|c|c|c|c|c|}
\hline Temperature & Photoperiod & Sex & Average days $\mathrm{s}^{\mathrm{a}}$ & $95 \% \mathrm{CL}^{\mathrm{b}}$ & Number \\
\hline \multirow[t]{4}{*}{$28^{\circ} \mathrm{C}$} & $16 \mathrm{~L}-8 \mathrm{D}$ & o & $5.6(4-6)$ & $\pm 0.16 \mathrm{a}$ & 50 \\
\hline & & $\hat{0}$ & $6.0(5-7)$ & $\pm 0.15 \mathrm{~b}$ & 48 \\
\hline & $12 \mathrm{~L}-12 \mathrm{D}$ & q & $5.9(5-7)$ & $\pm 0.12 b$ & 52 \\
\hline & & $\hat{o}$ & $6.3(5-7)$ & $\pm 0.13 \mathrm{c}$ & 66 \\
\hline \multirow[t]{4}{*}{$23^{\circ} \mathrm{C}$} & $16 \mathrm{~L}-8 \mathrm{D}$ & o & $8.6(8-10)$ & $\pm 0.16 \mathrm{a}$ & 54 \\
\hline & & $\hat{o}$ & $8.9(7-10)$ & $\pm 0.14 \mathrm{a}$ & 55 \\
\hline & $12 \mathrm{~L}-12 \mathrm{D}$ & q & $8.0(7-11)$ & $\pm 0.13 \mathrm{~b}$ & 64 \\
\hline & & $\hat{o}$ & $8.3(7-12)$ & $\pm 0.12 \mathrm{~b}$ & 52 \\
\hline \multirow[t]{4}{*}{$18^{\circ} \mathrm{C}$} & $16 \mathrm{~L}-8 \mathrm{D}$ & q & $15.0(14-17)$ & $\pm 0.22 \mathrm{a}$ & 36 \\
\hline & & $\hat{o}$ & $15.6(13-17)$ & $\pm 0.30 \mathrm{~b}$ & 48 \\
\hline & $12 \mathrm{~L}-12 \mathrm{D}$ & q & $14.8(13-17)$ & $\pm 0.14 \mathrm{a}$ & 46 \\
\hline & & $\hat{0}$ & $15.2(14-17)$ & $\pm 0.23 \mathrm{a}$ & 65 \\
\hline \multirow[t]{4}{*}{$13^{\circ} \mathrm{C}$} & $16 \mathrm{~L}-8 \mathrm{D}$ & q & $32.5(29-35)$ & $\pm 0.44 \mathrm{a}$ & 53 \\
\hline & & $\hat{\sigma}$ & $33.9(30-37)$ & $\pm 0.39 \mathrm{~b}$ & 49 \\
\hline & 12L-12D & $q$ & $31.1(27-34)$ & $\pm 0.37 \mathrm{c}$ & 40 \\
\hline & & $\hat{\sigma}$ & $32.9(30-36)$ & $\pm 0.60 \mathrm{a}$ & 57 \\
\hline
\end{tabular}

${ }^{a}$ Minimum and maximum durations are shown in parentheses.

${ }^{\mathrm{b}}$ Significant differences between different temperatures under all the photoperiods and in all sexes. Values followed by the same letter for each temperature are not significantly different under different photoperiods and sexes (ANOVA with Tukey's multiple comparisons, $p<0.05)$.

species was determined as $9.9^{\circ} \mathrm{C}$ (Kiritani, 1997), this temperature is only $3.1^{\circ} \mathrm{C}$ above the developmental zero. Furthermore, a part of L3 also prolongs their duration. The larvae in these instars develop cold hardiness when exposed to low temperatures (Kaneko, 1996). Larvae in these instars overwinter and are found in crop fields under deep snow (Kanehira and Torikura, 1988; Saito, 1988; Kaneko, 1996). Therefore, it is inferred that the larvae of the autumnal generation of A. gamma grow slowly at low temperatures under the shortday photoperiod. Further, their L4 duration with a part of L3 prolong and consequently, L4 larvae increase in number before winter. Thus, A. gamma has a clear developmental control response that is similar to the diapause in other species.

The spotted cutworm, Xestia c-nigrum also overwinters in the middle instar larval stage in diapause induced under the short-day photoperiod conditions. In this species, diapause larvae feed during the warm days. After overwintering, the larvae restart their development and pupate under longday conditions (Oku, 1984; Tsutsui et al., 1986). L4 duration in A. gamma prolongs at low temperature under the short-day photoperiod but its development continues slowly; hence, the prolonged duration of $A$. gamma larval development is believed to be an adaptation to the seasonal changes, similar to the diapause of larva in X. c-nigrum. However, the prolongation in A. gamma larval duration differs from the diapause in that the larval development continues without exposure under the longday photoperiod.

In Japan, A. gamma usually occurs in Hokkaido and has to face long winters that last for over five months. This species has not been reported to colonize in southern areas including Honshu where winter climatic conditions are not so severe. Thus overwintering feature of $A$. gamma in Japan differs from that of European populations. Further investigations regarding the fundamental ecology of the Japanese $A$. gamma population are necessary to understand its life history.

\section{ACKNOWLEDGEMENTS}

I thank Dr. C. Goto, National Agricultural Research Center, for providing information on the spotted cutworm and Dr. K. Yamamura, National Institute for Agro-Environmental Science for his advice on statistical analysis. Thanks are also due to the two anonymous reviewers for their helpful suggestions.

\section{REFERENCES}

Abdinbekova, A. A. and R. M. Akhmedov (1971) The influence of food plants on the development of certain noctuid moths in Azerbaijan. Zool. Zh. 50: 943-945. 
Kanehira, O. and H. Torikura (1988) Overwinter of the larvae of Autographa gamma Linnaeus. Annu. Rep. Plant Prot. North Japan 39: 218-219 (in Japanese).

Kaneko, J. (1993) Existence ratio of silver Y moth, Autographa gamma (L.) after overwintering in cabbage field at Sapporo, Japan. Annu. Rep. Plant Prot. North Japan 44: 124-126 (in Japanese).

Kaneko, J. (1996) Differences in cold-hardiness between silver-Y-moth, Autographa gamma (L.) and Asiatic common looper, A. nigrisigna (Walker). Jpn. J. Appl. Entomol. Zool. 40: 303-308 (in Japanese with English summary).

Kaneko, J., C. Kitamura, N. Sugawara, O. Kanehira, Y. Akiyama, O. Saito, K. Sato and H. Sugie (1990) Investigation of the annual prevalence of the silver $\mathrm{Y}$ moth (Autographa gamma L.) at different points in Hokkaido with synthetic sex pheromone traps. Annu. Rep. Plant Prot. North Japan 41: 164-166 (in Japanese).

Kiritani, K. (1997) The low development threshold temperature and the thermal constant in insects, mites and nematodes in Japan. Misc. Publ. Natl. Inst. Agro-Environ. Sci. 21: 1-71 (in Japanese with English summary).

Kitamura, C., J. Kaneko, O. Saito, H. Tsutsui and H. Sugie (1989) Investigation of the annual prevalence of the silver Y moth (Autographa gamma L.) with synthetic sex pheromone traps. Annu. Rep. Plant Prot. North Japan 40: 142-144 (in Japanese with English summary).

Oku, T. (1984) Larval diapause in the spotted cutworm, Xes- tia c-nigrum Linne (Lepidoptera: Noctuidae). Appl. Entomol. Zool. 19: 483-490.

Oku, T. and T. Kobayashi (1978) Migratory behaviors and life-cycle of noctuid moths (Insecta, Lepidoptera), with notes on the recent status of migrant species in northern Japan. Bull. Tohoku Natl. Agric. Exp. Stn. 58: 97-209 (in Japanese with English summary).

Saito, O. (1988) Notes on larval hibernation of the alfalfa looper, Autographa gamma (Linnaeus) on cabbage plant in Sapporo, Hokkaido. Annu. Rep. Plant Prot. North Japan 39: 217 (in Japanese with English summary).

Saito, O. (1997) Distribution of the silver Y moth, Autographa gamma (L.) (Lepidoptera: Noctuidae) and estimated life cycle in Japan. Annu. Rep. Plant Prot. North Japan 48: 204-206 (in Japanese).

Torikura, H. (1991) Mass overwintering of the larvae of Autographa gamma (L.) (Lepidoptera, Noctuidae) and relation to some meteorological factors. Annu. Rep. Plant Prot. North Japan 42: 130-132 (in Japanese).

Tsutsui, H., Y. Hirai and C. Goto (1986) Overwintering stage of the spotted cutworm in the Tokachi district, Hokkaido. Annu. Rep. Plant Prot. North Japan 37: 148-150 (in Japanese).

Tsutsui, H., C. Goto and O. Saito (1989) A simple rearing method for silver Y moth, Autographa gamma (Linnaeus). Annu. Rep. Plant Prot. North Japan 40: 132133 (in Japanese with English summary). 